\title{
Microstructure and Electro-Physical Properties of Sn-3.0Ag- 0.5Cu Nanocomposite Solder Reinforced with Ni Nanoparticles in the Melting-Solidification Temperature Range
}

\author{
A. Yakymovych ${ }^{1,2}$ (1) Yu. Plevachuk ${ }^{2}$ V. Sklyarchuk ${ }^{2} \cdot$ B. Sokoliuk ${ }^{2}$ • \\ T. Galya ${ }^{3}$ - H. Ipser ${ }^{1}$
}

Submitted: 14 November 2016/ Accepted: 26 February 2017/Published online: 10 March 2017

(c) The Author(s) 2017. This article is published with open access at Springerlink.com

\begin{abstract}
The electrical conductivity of nanocomposite Sn-3.0Ag-0.5Cu alloys with two different weight percentages of Ni nanoparticles (1.0 and 2.0 wt.\%) was measured over a wide temperature range. The samples were produced using a cold pressing method: $\mathrm{Sn}-3.0 \mathrm{Ag}-0.5 \mathrm{Cu}$ powder and $\mathrm{Ni}$ nanopowder were mechanically mixed and pressed into $8 \mathrm{~mm}$ diameter rods. Ni nanoparticles were synthesized via a chemical reduction method and characterized by a core/ shell structure. Temperature dependencies of the electrical conductivity revealed a hysteresis between the heating and cooling curves in a wide temperature range above the melting temperature. This fact is connected with structure transformations accompanied by a dissolution of $\mathrm{Ni}$ nanoparticles, which should be retarded due to an oxide/ hydroxide shell on the surface of the nanoparticles. A microstructure analysis of the samples in the solid state showed a fine distribution of intermetallic compounds in the Sn-based matrix. The $\mathrm{Ni}$ atoms substituted for $\mathrm{Cu}$
\end{abstract}

This article is an invited paper selected from presentations at TOFA 2016, the Discussion Meeting on Thermodynamics of Alloys, held September 4-9, 2016, in Santos, Brazil, and has been expanded from the original presentation.

A. Yakymovych

andriy.yakymovych@univie.ac.at

1 Department of Inorganic Chemistry - Functional Materials, University of Vienna, Althanstraße 14, 1090 Vienna, Austria

2 Department of Metal Physics, Ivan Franko National University of Lviv, Kyrylo i Mephodiy str. 8, Lviv 79005, Ukraine

3 School of Applied Science, Mongolian University of Sciences and Technology, 8th Khoroo, Baga toiruu 46/520, Ulaanbaatar 14191, Mongolia atoms in the $\mathrm{Cu}_{6} \mathrm{Sn}_{5}$ compound forming a $(\mathrm{Cu}, \mathrm{Ni})_{6} \mathrm{Sn}_{5}$ phase.

Keywords electrical conductivity $\cdot$ microstructure $\cdot \mathrm{Ni}$ nanoparticles $\cdot \mathrm{Sn}-3.0 \mathrm{Ag}-0.5 \mathrm{Ag} \cdot \mathrm{x}$-ray analysis

\section{Introduction}

The increasing scientific interest for Sn-based nanocomposite alloys with small additions of various metals, ${ }^{[-4]}$ oxides $^{[5-8]}$ and carbon ${ }^{[9-12]}$ in nanosized form relates to the possible application of these materials as an alternative to commercial lead-free solders. As pointed out in two literature reviews, ${ }^{[13,14]}$ improved mechanical properties and a reinforced microstructure of solder joints using nanocomposite $\mathrm{Sn}-\mathrm{Ag}-\mathrm{Cu}(\mathrm{SAC})$ alloys compared to those without nanoinclusions, revealed new possibilities for the development of currently used commercial lead-free solders. In general terms, the main profit of the nanosized additions is related to a suppression of the extensive growth of the $\mathrm{Cu}_{6} \mathrm{Sn}_{5}$ intermetallic compound (IMC) at the solder/Cu interface towards the solder side. This is achieved due to the spreading of nanoparticles over the IMC's surface, thereby suppressing the growth of $\mathrm{Cu}_{6} \mathrm{Sn}_{5}$ at the interface as well as in the bulk solder. In particular, the adsorbed nanoparticles at the IMC layer interface hinder the diffusion of $\mathrm{Sn}$ atoms from the bulk solder towards the interface and thereby suppress the IMC growth.

Compared to the solid state, there is a limited number of papers dealing with experimental investigations of nanocomposite SAC solders in the liquid state after melting as well as in the semi-solid state. ${ }^{[15-19]}$ It was shown that minor metal nanoadditions have an impact on the microstructure of solidified SAC solders, but practically 
without any significant change of the melting temperatures. ${ }^{[15-17]}$ Calorimetric measurements revealed that additions of $\mathrm{Co}$ in bulk and nanosized form to a liquid Sn3.8Ag-0.7Cu alloy resulted in additional heat effects during melting of the Co nanoparticles compared to those in bulk form. ${ }^{[19]}$ During the soldering process the solid joint is heated up to approx. $523 \mathrm{~K}$, while the melting temperature of the solder is near $490 \mathrm{~K}$. Therefore, metal nanoparticles should be partly or totally dissolved in the liquid SAC matrix. At this point, experimental data of thermophysical and thermodynamic properties as well as of the structure of the liquid nanocomposite SAC solders with additions of metal nanoparticles should provide necessary information for reliable simulations of the soldering processes.

$\mathrm{Ni}$ nanoparticles are among the most investigated metal nanoinclusions into lead-free solders due to their significant impact on the microstructure and mechanical properties of solders or solder joints. ${ }^{[18,20-23]}$ However, to the best of our knowledge, there are no literature data related to the structure and thermophysical properties of nanocomposite SAC solders with nano $\mathrm{Ni}$ additions in the liquid state after melting. In this work, we carried out investigations of the electrical conductivity of nanocomposite SAC in the liquid state. The samples were prepared from commercial Sn.3.0Ag-0.5 Cu powder and self-synthesized $\mathrm{Ni}$ nanopowder, where a chemical reduction method was used to produce the $\mathrm{Ni}$ nanoparticles.

\section{Experimental Methods}

\subsection{Synthesis of Nickel Nanoparticles}

The synthesis of $\mathrm{Ni}$ nanoparticles was performed via a chemical reduction method. Typically $0.5 \mathrm{~g}$ of nickel chloride $\left(\mathrm{NiCl}_{2} ;\right.$ AlfaAesar $)$ was dissolved in $60 \mathrm{ml}$ distilled water as the metal precursor under continued magnetic stirring (mixture A). Another solution was obtained by mixing $20 \mathrm{ml}$ of hydrazine monohydrate $\left(\mathrm{N}_{2} \mathrm{H}_{4} \cdot \mathrm{H}_{2} \mathrm{O}\right.$; AlfaAesar) and $1.0 \mathrm{~g}$ of sodium hydroxide ( $\mathrm{NaOH}$; AlfaAesar) as the reducing agent in $20 \mathrm{ml}$ distilled water (mixture B). Then $0.02 \mathrm{~g}$ polyvinylpyrrolidone (PVP) as surfactant agent was added to mixture $B$. At the end, mixture $B$ was added drop-wise into mixture $A$ under magnetic stirring until a strong dark color developed.

At an elevated temperature of $338 \mathrm{~K}$, nickel nanoparticles were formed after about $30 \mathrm{~min}$. The chemical reaction that reduced nickel chloride is given by:

$2 \mathrm{Ni}^{2+}+\mathrm{N}_{2} \mathrm{H}_{4}+4 \mathrm{OH}^{-} \rightarrow 2 \mathrm{Ni}+\mathrm{N}_{2}+4 \mathrm{H}_{2} \mathrm{O}$

After the reaction was complete, the obtained precipitates were separated from the remaining solution by centrifugation at $4000 \mathrm{rpm}$ for $30 \mathrm{~min}$, rinsed several times with a large amount of distilled water and absolute ethanol to remove the excess amount of surfactants, filtered, and finally dried in vacuum for one day at room temperature.

\subsection{Preparation of Nanocomposite Solders}

The composite $(\mathrm{SAC} 305)_{100-\mathrm{x}}(\mathrm{nanoNi})_{\mathrm{x}}$ alloys were prepared by mixing Sn-3.0Ag-0.5Cu (composition in mass\%; from now on SAC305) alloy in powder form (average particle size $31 \mu \mathrm{m}, \mathrm{SAC} 305$ powder, Kester, U.S.A.) with 1.0 and $2.0 \mathrm{wt} . \% \mathrm{Ni}$ nanoparticles (average size $250 \mathrm{~nm}$ ). Mechanical dispersion of the nanoparticles in the solder powder was achieved by mechanically mixing at room temperature for approximately $30 \mathrm{~min}$ using a Retsch mixer (Retsch MM301). After that the (SAC305) ${ }_{100-x}$ $(\text { nanoNi })_{\mathrm{x}}$ powders were pressed into pellet form (about $3 \mathrm{~mm}$ diameter and $10 \mathrm{~mm}$ height). All operations with $\mathrm{Ni}$ nanoparticles were performed in a glove box (M.Braun, LabMaster 130).
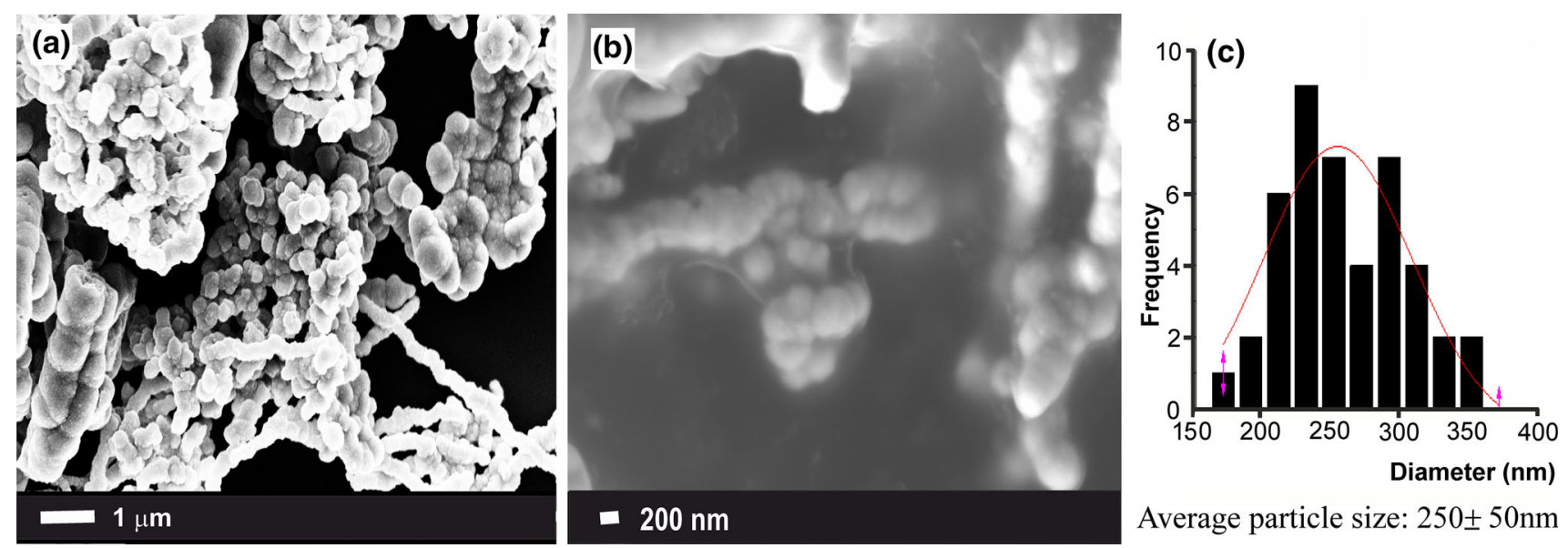

Average particle size: $250 \pm 50 \mathrm{~nm}$

Fig. 1 SEM images of as-synthesized Ni nanoparticles (a, b) and distribution of their particle sizes (c) 


\subsection{Electrical Conductivity Measurements}

The electrical conductivity measurements were carried out by the 4-point method in an argon atmosphere. Graphite electrodes for current and potential measurements were placed in the wall of the vertical cylindrical boron nitride ceramic measuring cell along its vertical axis. The potential electrodes were provided with thermocouples for temperature measurements. Single thermoelectrodes of these thermocouples were used for electrical conductivity determination. The melt temperature was determined by WRe-5/20 thermocouples located in close contact with the liquid. Further details of this method and its experimental realization have been described by Plevachuk and Sklyarchuk. ${ }^{[24]}$ Each sample was inserted into the cell directly inside a high-pressure vessel. Thus, the actual sample composition was accurate within a tolerance of $0.02 \mathrm{wt} . \%$. The resultant error of the electrical conductivity measurements is about $2 \%$.

\subsection{Materials Characterizations}

The crystal structure of the nanoparticles themselves and the phase composition of the samples after electrical conductivity measurements were analyzed on a Bruker D8 diffractometer at ambient temperature. The diffractometer operates in the $\theta / 2 \theta$ mode using $\mathrm{Ni}$-filtered $\mathrm{CuK}_{\alpha}$ radiation. Indexing of the phases was supported by the Inorganic Crystal Structural Database (ICSD). Rietveld refinement of the XRD patterns was done with the Topas $3^{\circledR}$ software provided by Bruker AXS. The morphology of as-synthesized nanoparticles and samples was observed by a

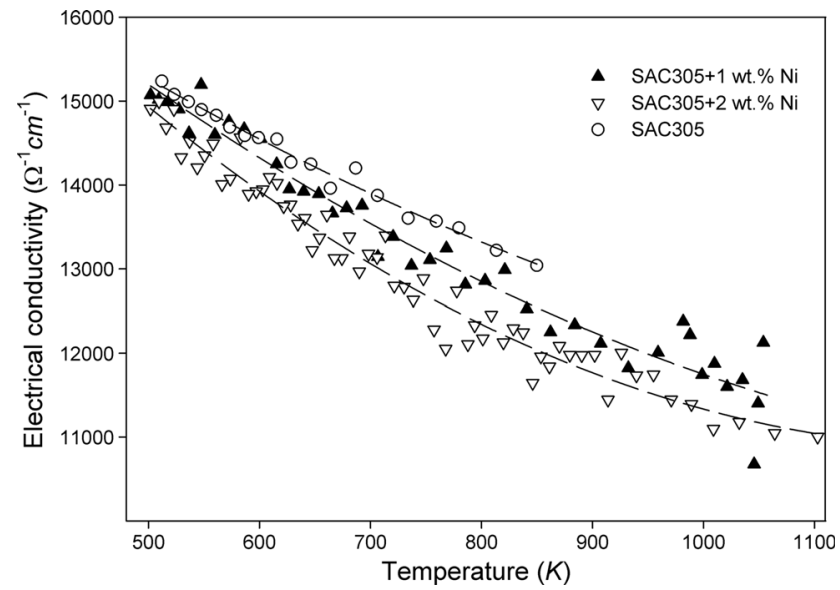

Fig. 4 Temperature dependence of the electrical conductivity for the liquid SAC305, SAC305 + 1 wt. $\% \mathrm{Ni}$ and SAC305 + 2 wt. $\% \mathrm{Ni}$ alloys on cooling

Fig. 2 x-ray pattern of assynthesized Ni nanoparticles
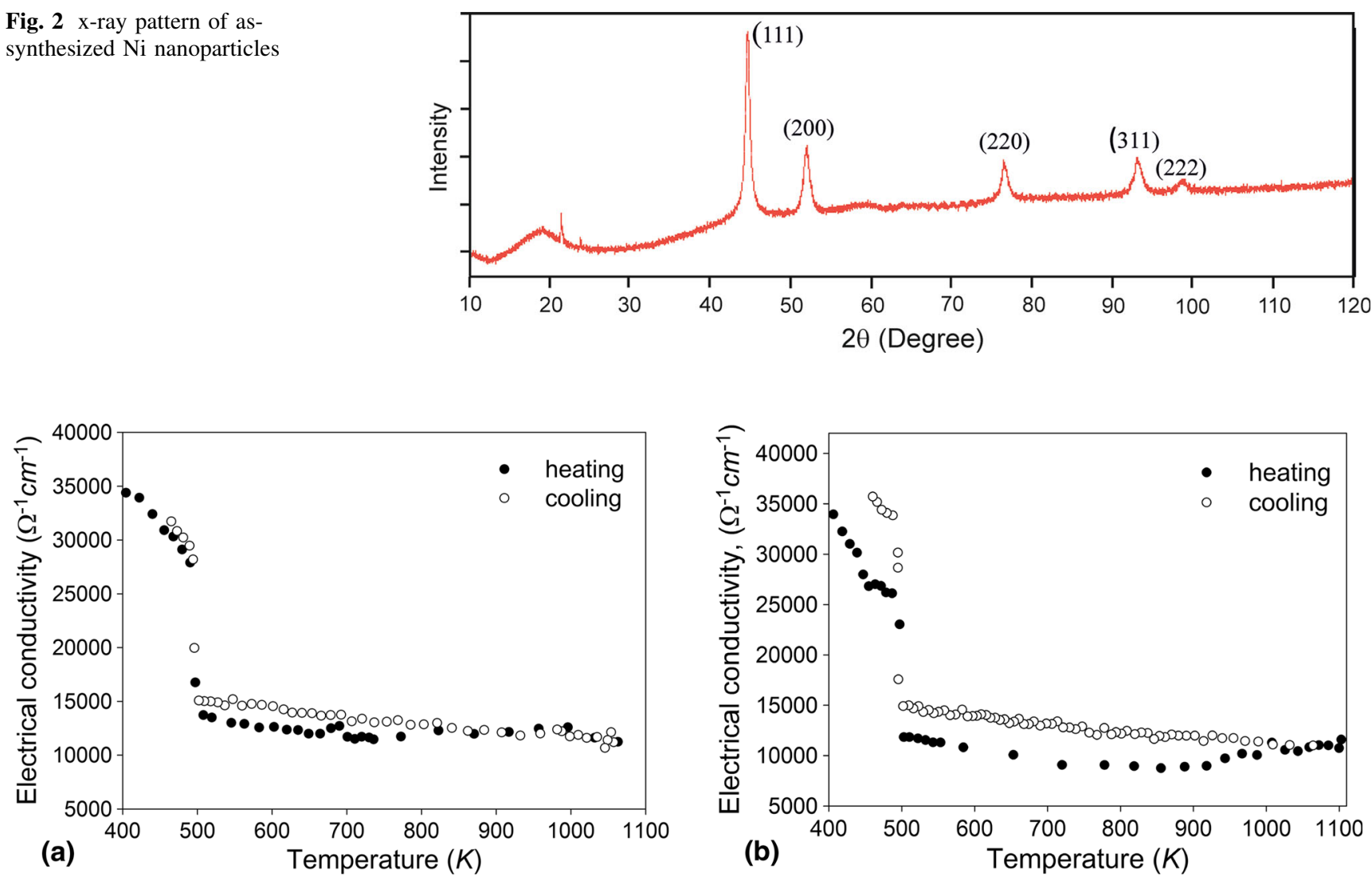

Fig. 3 Temperature dependence of the electrical conductivity for the liquid SAC305 +1 wt.\% Ni (a) and SAC305 + 2 wt.\% Ni (b) alloys 


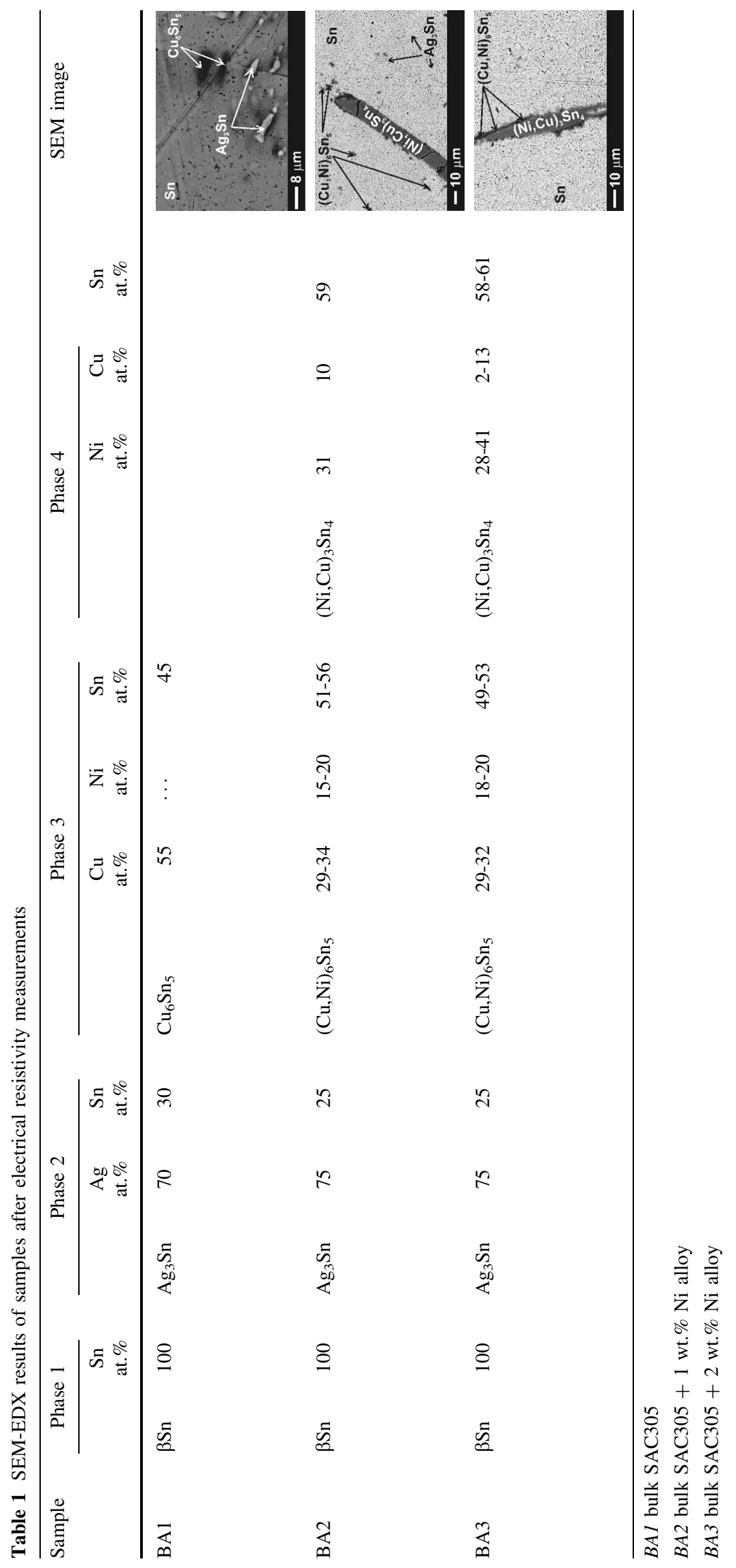


scanning electron microscope (SEM) Zeiss Supra 55 VP. The excitation energy of the electron beam was $15-20 \mathrm{kV}$; backscattered electrons (BSE) were detected in order to visualize the surfaces of the samples. The chemical analyses of the sample phases were performed using the energy dispersive $\mathrm{x}$-ray (EDX) technique with four characteristic spectral lines of $\mathrm{Ni}, \mathrm{Cu}(\mathrm{K}$-line) and $\mathrm{Ag}, \mathrm{Sn}$ (L-line).

\section{Results and Discussion}

SEM investigations of the morphology of as-synthesized $\mathrm{Ni}$ nanoparticles showed that they formed, rather randomly, large aggregations (Fig. 1a, b). SEM images with different magnification were used to estimate the average particle size of the Ni nanoparticles which was equal to $250 \pm 50 \mathrm{~nm}$ (Fig. 1c).

Figure 2 shows an x-ray diffraction pattern of as-synthesized Ni nanopowder which contains the peaks corresponding to the (111), (200), (220) (311) and (222) planes of Ni. According to the performed Rietveld refinement, the $\mathrm{Ni}$ nanoparticles have a cubic crystal structure (space group Fm-3 m).

The experimental temperature dependence of the electrical conductivity during heating and cooling with the same rate of $10 \mathrm{~K} / \mathrm{min}$ for liquid nanocomposite SAC305 alloys with different contents of $\mathrm{Ni}$ nanoparticles in the temperature range between $400 \mathrm{~K}$ and $1100 \mathrm{~K}$ are presented in Fig. 3. On reaching the melting temperature during heating, the electrical conductivity decreases abruptly from approx. $27,500 \Omega^{-1} \mathrm{~cm}^{-1}$ to $13,000 \Omega^{-1} \mathrm{~cm}^{-1}$ for $\operatorname{SAC} 305+1$ wt. $\% \mathrm{Ni}$, and from $27,000 \Omega^{-1} \mathrm{~cm}^{-1}$ to $12,000 \Omega^{-1} \mathrm{~cm}^{-1}$ for SAC305 +2 wt. $\% \mathrm{Ni}$. In the liquid state, the electrical conductivity gradually decreases with increasing temperature up to approx. $750 \mathrm{~K}$ for liquid SAC305 +1 wt. $\% \mathrm{Ni}$ alloy and to approx. $900 \mathrm{~K}$ in case of the liquid SAC305 +2 wt. $\%$ Ni alloy.

Further heating is accompanied by a slight increase of the electrical conductivity in both unreinforced SAC305 alloy and SAC305 alloys containing Ni nanoparticles. For the case of the melts containing $\mathrm{Ni}$ nanoparticles, this increase could be explained by dissolution of Ni nanoparticles in the SAC305 matrix. The dissolution process was completed at about $800 \mathrm{~K}$ in liquid SAC305 +1 wt. $\% \mathrm{Ni}$ and $900 \mathrm{~K}$ in liquid SAC305 +2 wt. $\% \mathrm{Ni}$. Cooling of the homogeneous melts from $1100 \mathrm{~K}$ is accompanied by a smooth increase of the electrical conductivity (Fig. 4).

Fitting the experimental data on cooling when $\mathrm{Ni}$ was dissolved completely in liquid solution (Fig. 4) with a parabolic function, the temperature dependence of the electrical conductivity (in $\Omega^{-1} \mathrm{~cm}^{-1}$ ) can be approximated by the following relationship:
$\sigma(T)=20970-13.9 T+0.0046 T^{2}$

for $\mathrm{SAC} 305+1 \mathrm{wt} . \% \mathrm{Ni}$ within the temperature range between about 500 and $1050 \mathrm{~K}$ and

$\sigma(T)=22100-18 T+0.0072 T^{2}$

for SAC305 +2 wt. $\% \mathrm{Ni}$ within the temperature range between about 500 and $1100 \mathrm{~K}$.

The electrical conductivity of the SAC305 alloy is slightly higher than the conductivity of the liquid alloys containing Ni nanoparticles. At the same time, the absolute conductivity values for $\mathrm{SAC} 305+1 \mathrm{wt} . \% \mathrm{Ni}$ are somewhat higher than those for SAC305 +2 wt. $\% \mathrm{Ni}$. It is suggested that the $\mathrm{Ni}$ atoms form additional centers of electron scattering, and that an increase of the $\mathrm{Ni}$ content leads thus to a decrease of the electrical conductivity.

The microstructure phase composition of the alloys was analyzed after the electrical conductivity measurements using SEM-EDX and x-ray diffraction. The results of the phase analysis along with BSE images of three selected alloys are collected in Table 1. According to the obtained results, no residual pure $\mathrm{Ni}$ was found in the samples but the $\mathrm{Ni}$ atoms rather substitute for $\mathrm{Cu}$ atoms in the $\mathrm{Cu}_{6} \mathrm{Sn}_{5}$ crystals. A similar substitution was reported by Tay et al. ${ }^{[20]}$ who studied the influence of nano $\mathrm{Ni}$ additions on the morphology and growth of intermetallic compounds at the interface of SAC387/Cu solder joint.

Furthermore, SEM analysis showed that $\mathrm{Cu}$, on the other hand, substitutes for $\mathrm{Ni}$ atoms in the intermetallic compound $\mathrm{Ni}_{3} \mathrm{Sn}_{4}$ IMCs. Unlike the finely dispersed small microregions of the $(\mathrm{Cu}, \mathrm{Ni})_{6} \mathrm{Sn}_{5}$ phase, $(\mathrm{NiCu})_{3} \mathrm{Sn}_{4}$ crystals are present in the form of relative large needles.

\section{Conclusions}

The electrical conductivity of nanocomposite SAC305 alloys without and with two different weight percentages of $\mathrm{Ni}$ nanoparticles (1.0 and $2.0 \mathrm{wt} . \%$ ) was determined. A hysteresis between the heating and cooling curves of the electrical conductivity over a wide temperature range above the melting point is explained by dissolution of $\mathrm{Ni}$ nanoparticles in the SAC305 matrix during heating. Cooling of the homogeneous melts from $1100 \mathrm{~K}$ is accompanied by a smooth increase of the electrical conductivity.

Higher absolute electrical conductivity values of liquid SAC $305+1$ wt. $\% \mathrm{Ni}$ as compared to the conductivity of liquid SAC305 +2 wt.\% $\mathrm{Ni}$ is due to the fact that the $\mathrm{Ni}$ atoms form additional centers of electron scattering, and an increase of the Ni content leads to a decrease of the electrical conductivity. 
The microstructure analysis of the samples in the solid state showed a fine distribution of intermetallic compounds in the Sn-based matrix. The $\mathrm{Ni}$ atoms substitute the $\mathrm{Cu}$ atoms in the $\mathrm{Cu}_{6} \mathrm{Sn}_{5}$ compound forming $(\mathrm{Cu}, \mathrm{Ni})_{6} \mathrm{Sn}_{5}$ crystals.

Acknowledgments Open access funding provided by University of Vienna. Financial support for this study came from the Austrian Science Fund (FWF) under Project Nos. P26304 and P27049. The authors also want to acknowledge the help of Dr. Ali Roshanghias of the CTR Carinthian Tech Research (Villach, Austria) with the Ni nanoparticles production and Dr. St. Puchegger of the Faculty of Physics, University of Vienna, with the SEM studies.

Open Access This article is distributed under the terms of the Creative Commons Attribution 4.0 International License (http://crea tivecommons.org/licenses/by/4.0/), which permits unrestricted use, distribution, and reproduction in any medium, provided you give appropriate credit to the original author(s) and the source, provide a link to the Creative Commons license, and indicate if changes were made.

\section{References}

1. A.S.M.A. Haseeb, M.M. Arafat, and M.R. Johan, Stability of Molybdenum Nanoparticles in $\mathrm{Sn}-3.8 \mathrm{Ag}-0.7 \mathrm{Cu}$ Solder During Multiple Reflow and Their Influence on Interfacial Intermetallic Compounds, Mater. Charact., 2012, 64, p 27-35

2. T. Fouzder, Q.Q. Li, Y.C. Chan, and D.K. Chan, Interfacial Microstructure and Hardness of Nickel (Ni) Nanoparticle-Doped Tin-Silver-Copper (Sn-Ag-Cu) Solders on Immersion Silver (Ag)-Plated Copper ( $\mathrm{Cu}$ ) Substrates, J. Mater. Sci. Mater. Electron., 2014, 25(9), p 4012-4023

3. L. Sun, L. Zhang, L. Xu, S.J. Zhong, J. Ma, and L. Bao, Effect of Nano-Al Addition on Properties and Microstructure of Low-Ag Content Sn-1Ag-0.5Cu Solders, J. Mater. Sci. Mater. Electron., 2016, 27(7), p 7665-7673

4. A. Yakymovych, Y. Plevachuk, P.S. Svec, D. Janicvokic, P. Sebo, N. Beronska, M. Nosko, L. Orovcik, A. Roshanghias, H. Ipser, Nanocomposite SAC Solders: Morphology, Electrical and Mechanical Properties of Sn-3.8Ag-0.7Cu Solders by Adding Co Nanoparticles. J. Mater. Sci. Mater. Electron. (2016) (under review)

5. K. Mehrabi, F. Khodabakhshi, E. Zareh, A. Shahbazkhan, and A. Simchi, Effect of Alumina Nanoparticles on the Microstructure and Mechanical Durability of Meltspun Lead-Free Solders Based on Tin Alloys, J. Alloy Compd., 2016, 688, p 143-155

6. Y. Gu, X.C. Zhao, Y. Li, Y. Liu, Y. Wang, and Z.Y. Li, Effect of Nano-Fe2O3 Additions on Wettability and Interfacial Intermetallic Growth of Low-Ag Content Sn-Ag-Cu Solders on $\mathrm{Cu}$ Substrates, J. Alloys Compd., 2015, 627, p 39-47

7. A. Yakymovych, Y. Plevachuk, P.S. Svec, P. Svec, D. Janicvokic, P. Sebo, N. Beronska, A. Roshanghias, and H. Ipser, Morphology and Shear Strength of Lead-Free Solder Joints with Sn3.0Ag0.5Cu Solder Paste Reinforced with Ceramic Nanoparticles, J. Electron. Mater., 2016, doi:10.1007/s11664-016-4832-7

8. A. Roshanghias, A.H. Kokabi, Y. Miyashita, Y. Mutoh, M. Rezayat, and H.R. Madaah-Hosseini, Ceria Reinforced Nanocomposite Solder Foils Fabricated by Accumulative Roll
Bonding Process, J. Mater. Sci. Mater. Electron., 2012, 23(9), p 1698-1704

9. D.L. Ma and P. Wu, Improved Microstructure and Mechanical Properties for Sn58Bi0.7Zn Solder Joint by Addition of Graphene Nanosheets, J. Alloys Compd., 2016, 671, p 127-136

10. E.K. Choi, K.Y. Lee, and T.S. Oh, Fabrication of Multiwalled Carbon Nanotubes-Reinforced Sn Nanocomposites for Lead-Free Solder by an Electrodeposition Process, J. Phys. Chem. Solids, 2008, 69(5-6), p 1403-1406

11. X.D. Liu, Y.D. Han, H.Y. Jing, J. Wei, and L.Y. Xu, Effect of Graphene Nanosheets Reinforcement on the Performance of SnAg-Cu Lead-Free Solder, Mat. Sci. Eng. A, 2013, 562, p 25-32

12. Y.L. Huang, Z.Y. Xiu, G.H. Wu, Y.H. Tian, and P. He, Sn3.0Ag-0.5Cu Nanocomposite Solders Reinforced by Graphene Nanosheets, J. Mater. Sci. Mater. Electron., 2016, 27(7), p 68096815

13. A.T. Tan, A.W. Tan, and F. Yusof, Influence of Nanoparticle Addition on the Formation and Growth of Intermetallic Compounds (IMCs) in $\mathrm{Cu} / \mathrm{Sn}-\mathrm{Ag}-\mathrm{Cu} / \mathrm{Cu}$ Solder Joint During Different Thermal Conditions, Sci. Technol. Adv. Mat., 2015, 16(3), p 033505

14. J. Shen and Y.C. Chan, Research Advances in Nano-Composite Solders, Microelectron. Reliab., 2009, 49(3), p 223-234

15. A. Yakymovych, S. Mudry, I. Shtablavyi, and H. Ipser, Effect of Nano Co Reinforcements on the Structure of the Sn-3.0Ag- $0.5 \mathrm{Cu}$ Solder in Liquid and After Reflow Solid States, Mater. Chem. Phys., 2016, 181, p 470-475

16. K. Bukat, M. Koscielski, J. Sitek, M. Jakubowska, and A. Mlozniak, Silver Nanoparticles Effect on the Wettability of SnAg-Cu Solder Pastes and Solder Joints Microstructure on Copper, Solder. Surf. Mt. Tech., 2011, 23(3), p 150-160

17. S.L. Tay, A.S.M.A. Haseeb, and M.R. Johan, Addition of Cobalt Nanoparticles into Sn-3.8Ag-0.7Cu Lead-Free Solder by Paste Mixing, Solder. Surf. Mt. Tech., 2011, 23(1), p 10-14

18. A.K. Gain and Y.C. Chan, The Influence of a Small Amount of $\mathrm{Al}$ and Ni Nano-Particles on the Microstructure, Kinetics and Hardness of $\mathrm{Sn}-\mathrm{Ag}-\mathrm{Cu}$ solder on OSP-Cu Pads, Intermetallics, 2012, 29, p 48-55

19. A. Yakymovych, G. Kaptay, A. Roshanghias, H. Flandorfer, and H. Ipser, Enthalpy Effect of Adding Cobalt to Liquid Sn-3.8Ag$0.7 \mathrm{Cu}$ Lead-Free Solder Alloy: Difference Between Bulk and Nanosized Cobalt, J. Phys. Chem. C, 2016, 120, p 1881-1890

20. S.L. Tay, A.S.M.A. Haseeb, M.R. Johan, P.R. Munroe, and M.Z. Quadir, Influence of Ni Nanoparticle on the Morphology and Growth of Interfacial Intermetallic Compounds Between Sn3.8Ag- $0.7 \mathrm{Cu}$ Lead-Free Solder and Copper Substrate, Intermetallics, 2013, 33, p 8-15

21. V.L. Niranjani, B.S.S.C. Rao, R. Sarkar, and S.V. Kamat, The Influence of Addition of Nanosized Molybdenum and Nickel Particles on Creep Behavior of Sn-Ag Lead Free Solder Alloy, J. Alloy Comd., 2012, 542, p 136-141

22. M.N. Bashir, A.S.M.A. Haseeb, A.M.S. Rahman, M.A. Fazal, and C.R. Kao, Reduction of Electromigration Damage in SAC305 Solder Joints by Adding Ni Nanoparticles Through Flux Doping, J. Mater. Sci., 2015, 50(20), p 6748-6756

23. X.C. Zhang, J.W. Cheng, B. Zheng, X.C. Zhao, Y. Liu, and P. Chen, Nickel Nanoparticles Mediated Growth of the Intermetallic Compound Between Sn-1.0Ag-Xni Solders Alloy and Cu Substrate, Mater. Sci. Forum, 2015, 815, p 8807-8813

24. Y. Plevachuk and V. Sklyarchuk, Electrophysical Measurements for Strongly Aggressive Liquid Semiconductors, Meas. Sci. Technol., 2001, 12(1), p 23-26 